\title{
Consumo e desempenho de cordeiros e borregos alimentados com dietas de alto concentrado de milho ou sorgo
}

[Intake and performance of lambs and hoggets fed high concentrate corn or sorghum diets]

\author{
R.S. Venturini ${ }^{1}$, S. Carvalho ${ }^{2}$, C.C. Pires ${ }^{2,5}$, P. S. Pacheco ${ }^{2}$, A.C.R.S. Pellegrin ${ }^{1}$, A.B. Moro ${ }^{1}$, \\ J.F. Lopes $^{3}$, A. A. Martins ${ }^{1}$, G.M.C. Bernardes ${ }^{1}$, R.R. Simões ${ }^{1}$, A.L. Menegon ${ }^{4}$, J.H. Motta ${ }^{4}$ \\ ${ }^{1}$ Aluno de pós-graduação - Universidade Federal de Santa Maria - Santa Maria, RS \\ ${ }^{2}$ Universidade Federal de Santa Maria - Santa Maria, RS \\ ${ }^{3}$ Aluna de pós-graduação - Universidade Federal do Rio Grande do Sul - Porto Alegre, RS \\ ${ }^{4}$ Aluno de graduação - Universidade Federal de Santa Maria - Santa Maria, RS \\ ${ }^{5}$ Bolsista de Produtividade do CNPq
}

\begin{abstract}
RESUMO
Objetivou-se avaliar os consumos de matéria seca, nutrientes e desempenho na terminação de cordeiros e borregos submetidos a dietas de alto concentrado de grão de milho ou sorgo. Foram utilizados 32 animais, sendo 16 cordeiros (dente de leite) e 16 borregos (dois dentes) da raça Corriedale. As dietas eram constituídas de feno de aveia- branca (Avena sativa), grão de milho (Zea mays) ou de sorgo (Sorghum bicolor (L.) Moench), farelo de soja (Glycine Max), calcário calcítico, bicarbonato de sódio e monensina. Os cordeiros apresentaram superioridade $(\mathrm{P} \leq 0,05)$ quanto ao $\mathrm{CMS}\left(\%\right.$ do $\mathrm{PV}$ e $\left.\mathrm{g} / \mathrm{kg} \mathrm{PV}^{0,75}\right)$, ao CPB $\left(\mathrm{kg} / \mathrm{dia}, \%\right.$ do PV e g/kg PV ${ }^{0,75}$ ), ao CEE (\% do PV), ao CFDN e ao CFDA (\% do PV e g/kg PV ${ }^{0,75}$ ), ao CNDT (\% do PV), ao ganho de peso médio diário, à conformação in vivo e à conversão alimentar. Por outro lado, o CEE, o CCHT e o CCNE (kg/dia), o peso vivo inicial, o peso vivo final e o peso vivo ao abate foram superiores $(\mathrm{P} \leq 0,05)$ na categoria dos borregos. Em relação aos grãos avaliados, verificou-se maior $(\mathrm{P} \leq 0,05)$ CEE $\left(\mathrm{kg} / \mathrm{dia}, \%\right.$ do $\mathrm{PV}$ e g/kg $\left.\mathrm{PV}^{0,75}\right)$ e menor $(\mathrm{P} \leq 0,05)$ CFDN $(\%$ do PV) e CFDA $\left(\mathrm{kg} /\right.$ dia, \% do $\mathrm{PV}$ e $\left.\mathrm{g} / \mathrm{kg} \mathrm{PV}^{0,75}\right)$ para os animais alimentados com dieta de alto concentrado à base de grão de milho em relação àqueles alimentados com grão de sorgo. Os cordeiros apresentam consumos relativos superiores aos borregos, porém sua resposta zootécnica é maior. O uso de dietas de alto concentrado de sorgo ou de milho proporcionou resultados semelhantes.
\end{abstract}

Palavras-chave: categorias, confinamento, ovino

\begin{abstract}
This study aimed to evaluate the dry matter, nutrient intake, and performance on feedlot of lambs and hoggets submitted to corn or sorghum high concentrate diets. Thirty-two Corriedale animals, being 16 lambs (milk teeth) and 16 hoggets (two teeth) were used. The diets were composed of white oat hay (Avena sativa), corn (Zea mays) or sorghum grain (Sorghum bicolor (L.) Moench), soybean meal (Glycine Max), limestone, sodium bicarbonate, and monensin. The lambs presented a superiority $(P \leq 0.05)$ regarding the DMI (\% of $L W$ and $\left.\mathrm{g} / \mathrm{kg} \mathrm{L} W^{0.75}\right), C P I\left(\mathrm{~kg} /\right.$ day, \% of $L W$ and $\left.\mathrm{g} / \mathrm{kg} \mathrm{LW} W^{0.75}\right), E E I(\%$ of $L W$ ), NDFI and ADFI (\% of $L W$ and $\mathrm{g} / \mathrm{kg} \mathrm{L} \mathrm{W}^{0.75}$ ), TDNI (\% of LW), daily average weight gain, conformation in vivo and feed conversion. On the other hand, the EEI, TCI, and NSCI (kg/day), the initial live weight, final live weight and the live weight at slaughter were superior $(P \leq 0.05)$ in the hoggets category. In relation to the evaluated grains, a higher $(P \leq 0.05)$ EEI ( $\mathrm{kg} /$ day, \% of LW and $\left.\mathrm{g} / \mathrm{kg} \mathrm{LW} \mathrm{W}^{0.75}\right)$ and a lower $(P \leq 0.05)$ NDFI (\% of LW) and ADFI ( $\mathrm{kg} /$ day, \% of LW and $\left.\mathrm{g} / \mathrm{kg} \mathrm{LW} \mathrm{W}^{0.75}\right)$ were verified for the animals fed with high concentrate diets based on corn grain in relation to those fed with sorghum grain. The lambs presented an intake relatively superior to the hoggets, however their zootechnical response is higher. The use of high concentrate diets of sorghum or corn provides similar results.
\end{abstract}

Keywords:categories, feedlot, sheep

Recebido em 2 de novembro de 2015

Aceito em 12 de maio de 2016

E-mail: rs_venturini@hotmail.com 


\section{INTRODUÇÃO}

A procura por produtos oriundos da ovinocultura vem ganhando destaque no cenário econômico, principalmente em relação ao consumo de carnes. Dessa maneira, constata-se um indicador potencial para a expansão da atividade. Contudo, devem-se buscar alternativas capazes de apresentar a melhor eficiência produtiva. Nesse sentido, Medeiros et al. (2009) comentam que a utilização do confinamento é uma alternativa viável para o aumento da oferta de carne ovina, pois permite a produção desses animais em grande escala em pequenas áreas.

Em se tratando do desempenho produtivo e econômico da terminação de ovinos em confinamento, um importante fator a ser considerado é a alimentação que será fornecida para os animais. Nesse contexto, a utilização de dietas com grande participação de concentrado vem se tornando financeiramente atraente nos últimos anos e com boa funcionalidade operacional. Para Sormunen-Cristian et al. (2013), a escassez de volumosos de boa qualidade e de preços baixos de alguns grãos incentiva o uso de dietas à base de concentrado para terminação de ovinos. Contudo, de acordo com Moreno et al. (2010), o fornecimento de maiores quantidades de concentrados no confinamento aumenta o risco de ocorrência de distúrbios metabólicos, o que pode comprometer o consumo de nutrientes e, consequentemente, o desempenho animal. Assim, faz-se necessário avaliar o efeito do uso de dietas com grande participação de concentrados sobre o consumo e o desempenho produtivo dos animais.

Outro ponto que deve ser destacado são os ingredientes utilizados na composição das dietas de alto concentrado, e a escolha por alimentos energéticos é de suma importância para o sucesso dessa dieta. Araújo Filho et al. (2010) demonstram que animais alimentados com maiores quantidades de energia na dieta apresentam melhor desempenho. Nesse sentido, a utilização de dietas à base de grão de milho ou de sorgo torna-se uma alternativa interessante para obtenção de bons resultados produtivos em animais confinados. Além disso, esses grãos apresentam grande palatabilidade e aceitabilidade pelos animais e também fácil disponibilidade para os produtores.
O rebanho ovino é composto por diferentes categorias, e a maior parte das pesquisas está baseada na categoria dos cordeiros. Porém, a categoria dos borregos possui grande participação na produção ovina. Portanto, a categoria animal é outro fator importante a ser levado em consideração, pois existem diferenças fisiológicas entre animais de idades distintas, as quais refletem diretamente sobre o consumo de alimentos e o desempenho animal. Pazdiora et al. (2014) comentam que animais mais jovens são mais eficientes que animais mais velhos.

Desse modo, o objetivo do presente trabalho foi avaliar o consumo de matéria seca, de nutrientes e o desempenho na terminação em confinamento de cordeiros e borregos alimentados com dietas de alto concentrado à base de grão de milho ou de sorgo.

\section{MATERIAL E MÉTODOS}

O trabalho foi conduzido no Laboratório de Ovinocultura do Departamento de Zootecnia da Universidade Federal de Santa Maria, Santa Maria, RS, no período de novembro de 2013 a janeiro de 2014. A região, fisiograficamente denominada Depressão Central, possui altitude de $95 \mathrm{~m}$, latitude de $29^{\circ} 43^{\prime}$ Sul e longitude de 5342' Oeste, sendo o clima do tipo Cfa (subtropical úmido), segundo a classificação de Köppen (Moreno, 1961). Este experimento foi conduzido de acordo com as normas éticas e foi aprovado pelo Comitê Interno de Ética em Experimentação Animal da mesma instituição (Protocolo 059/2014).

Foram utilizados 32 ovinos da raça Corriedale, sendo 16 cordeiros (dentes de leite) e 16 borregos (dois dentes), machos castrados, todos oriundos do mesmo rebanho e, portanto, com genótipo semelhante. Os animais foram distribuídos em um delineamento experimental inteiramente ao acaso, em esquema fatorial $2 \times 2$ (duas categorias ovinas $\mathrm{x}$ dois grãos), com oito repetições por tratamento, que consistiram em: cordeiros alimentados com dieta de alto concentrado de milho; cordeiros alimentados com dieta de alto concentrado de sorgo; borregos alimentados com dieta de alto concentrado de milho e borregos alimentados com dieta de alto concentrado de sorgo. 
Os animais foram confinados em baias individuais, totalmente cobertas, com piso ripado, com dimensão de $2 \mathrm{~m}^{2}$ cada. Todas as baias eram providas de comedouros e bebedouros individuais, onde foi fornecida alimentação e água para os animais. A dieta foi formulada para ser isoproteica, para cada categoria, sendo constituída de feno de aveiabranca (Avena sativa) e grão de milho (Zea mays) ou sorgo (Sorghum bicolor (L.) Moench), fornecido inteiro. Para atender as exigências das categorias de proteína bruta e minerais, foi adicionado farelo de soja (Glycine Max) e calcário calcítico, respectivamente, de acordo com o Nutrient... (2007), para a obtenção de ganho de peso de $200 \mathrm{~g} /$ dia. Também se utilizou bicarbonato de sódio $\left(\mathrm{NaHCO}_{3}\right)$ na proporção de $1 \%$ do total oferecido da MS, monensina sódica (Rumensin), de acordo com as recomendações do fabricante, e sal comum, fornecido à vontade, em recipientes individuais. A dieta foi oferecida na forma de mistura total, em uma relação volumoso:concentrado de 10:90, com base na matéria seca.

$\mathrm{Na}$ Tab. 1, está apresentada a composição químico-bromatólogica dos alimentos utilizados e, na Tab. 2, a proporção dos ingredientes e a composição bromatológica das dietas experimentais.

A ração foi ofertada aos animais ad libitum, uma vez ao dia, sendo o horário de arraçoamento às oito horas. A quantidade ofertada foi ajustada em função da sobra observada diariamente, e esta deveria ser $10 \%$ da quantidade oferecida no dia anterior, de modo a garantir o consumo voluntário máximo dos animais. Os consumos foram determinados pela diferença entre 0 oferecido na dieta e as sobras (com base na matéria seca), obtendo-se os consumos diários de matéria seca, proteína bruta, extrato etéreo, fibra em detergente neutro, fibra em detergente ácido, carboidratos totais, carboidratos não estruturais e nutrientes digestíveis totais.

O período experimental foi precedido de 10 dias para adaptação dos animais ao alimento, às condições de instalações e ao manejo. Nessa fase, para aprendizado de consumo de alimento sólido no comedouro por parte dos animais, foi fornecido feno de alfafa (Medicago sativa) triturado, como parte da alimentação. Posteriormente, até o início do período experimental, a cada dois dias, o feno de alfafa era substituído gradativamente em uma proporção de $25 \%$ pela dieta a ser utilizada, conforme o tratamento no qual o animal se encontrava. O ensaio de alimentação iniciou após o período de adaptação, estendendo-se até o momento em que cada cordeiro ou borrego atingiu o escore de condição corporal 3,0 (escala de 1 a 5 , com intervalos de 0,25 , em que 1 é considerado excessivamente magro e 5 excessivamente gordo), quando era destinado ao abate.

Tabela 1. Teores médios de matéria seca (MS), matéria orgânica (MO), proteína bruta (PB), extrato etéreo (EE), fibra em detergente neutro (FDN), fibra em detergente ácido (FDA), carboidratos totais (CHT), carboidratos não estruturais (CNE), cinzas (CIN), nutrientes digestíveis totais (NDT), cálcio (Ca) e fósforo $(\mathrm{P})$, dos ingredientes utilizados na formulação das dietas experimentais

\begin{tabular}{cccccccc}
\hline Item $(\%)$ & $\begin{array}{c}\text { Feno de } \\
\text { aveia }\end{array}$ & $\begin{array}{c}\text { Milho, } \\
\text { grão }\end{array}$ & $\begin{array}{c}\text { Sorgo, } \\
\text { grão }\end{array}$ & Farelo de soja & $\begin{array}{c}\text { Bicarbonato } \\
\text { de sódio }\end{array}$ & $\begin{array}{c}\text { Calcário } \\
\text { calcítico }\end{array}$ & $\begin{array}{c}\text { Monensina } \\
\text { sódica }\end{array}$ \\
\hline MS & 89,99 & 90,98 & 90,70 & 92,50 & 99,00 & 99,27 & 98,00 \\
MO & 92,84 & 98,95 & 98,67 & 93,39 & - & - & - \\
PB & 5,94 & 8,96 & 8,42 & 52,30 & - & - & - \\
EE & 1,87 & 5,36 & 4,30 & 3,89 & - & - & - \\
FDN & 64,36 & 9,84 & 11,60 & 16,16 & - & - & - \\
FDA & 36,80 & 1,53 & 5,51 & 5,88 & - & - & - \\
CHT & 85,02 & 84,64 & 85,96 & 37,20 & - & - & - \\
CNE & 20,67 & 74,79 & 74,35 & 21,04 & - & - & - \\
CIN & 7,16 & 1,05 & 1,33 & 6,61 & - & - & - \\
NDT & 55,58 & 86,03 & 78,80 & 80,73 & - & - & - \\
$\mathrm{Ca}^{1}$ & 0,44 & 0,03 & 0,04 & 0,33 & - & 37,70 & - \\
$\mathrm{P}^{1}$ & 0,24 & 0,25 & 0,28 & 0,88 & - & 0,02 & - \\
\hline
\end{tabular}

${ }^{1}$ Valor tabelado (Valadares Filho et al., 2006). 
Consumo e desempenho...

Tabela 2. Proporção dos ingredientes (\% MS) e composição bromatológica das dietas experimentais

\begin{tabular}{ccccc}
\hline & \multicolumn{5}{c}{ Tratamentos } \\
\hline & Cordeiro milho & Cordeiro sorgo & Borrego milho & Borrego sorgo \\
\hline Feno de aveia & 10,00 & Proporção dos ingredientes (\% MS) & 10,00 \\
Milho, grão & 60,82 & 10,00 & 10,00 & - \\
Sorgo, grão & - & - & 77,81 & 76,67 \\
Farelo de soja & 26,04 & 59,92 & - & 10,47 \\
Bicarbonato de sódio & 1,00 & 26,81 & 9,48 & 1,00 \\
Calcário calcítico & 2,11 & 1,00 & 1,00 & 0,034 \\
Monensina sódica & 0,034 & 2,24 & 1,67 & \\
\hline & Composição bromatológica (\% MS) & 0,034 & 91,06 \\
MS & 91,53 & 91,39 & 97,55 \\
MO & 96,90 & 96,68 & 91,24 \\
PB & 19,66 & 19,66 & 97,82 & 12,52 \\
EE & 4,46 & 3,81 & 12,52 & 17,02 \\
FDN & 16,63 & 17,72 & 4,72 & 8,52 \\
FDA & 6,14 & 8,56 & 15,63 & 78,30 \\
CHT & 69,66 & 69,98 & 5,43 & 61,28 \\
CNE & 53,03 & 52,26 & 77,89 & 2,43 \\
CIN & 3,07 & 3,28 & 62,26 & 74,46 \\
NDT & 78,93 & 74,45 & 2,16 & 2,50 \\
Ca/P & 2,50 & 2,50 & 80,18 & 2,50 \\
\hline
\end{tabular}

(MS) matéria seca; (MO) matéria orgânica; (PB) proteína bruta; (EE) extrato etéreo; (FDN) fibra em detergente neutro; (FDA) fibra em detergente ácido; (CHT) carboidratos totais; (CNE) carboidratos não estruturais; (CIN) cinzas; (NDT) nutrientes digestíveis totais; (Ca) cálcio; (P) fósforo.

As medidas de controle sanitário foram executadas no início do período de adaptação e repetidas quando necessário, durante o período experimental, para o controle de endoparasitas. Os animais também foram vacinados contra carbúnculo sintomático, gangrena gasosa e enterotoxemia.

Foram realizadas pesagens no início e no final da fase experimental, após jejum de sólidos de 14 horas, e, para um melhor acompanhamento do desempenho, foram realizadas pesagens intermediárias a cada 14 dias.

Além disso, foram coletadas, a cada dois dias, amostras das sobras ( $10 \%$ do peso total) e dos alimentos oferecidos, sendo feitas amostras compostas por animal no final do período experimental. Estas foram acondicionadas em sacos plásticos identificados e armazenadas em freezer a $-10^{\circ} \mathrm{C}$, para posteriores análises laboratoriais. As amostras dos alimentos fornecidos e as sobras foram pré-secas em estufa ventilada a $55^{\circ} \mathrm{C}$ por aproximadamente 72 horas e, posteriormente, moídas em moinho tipo "Willey" com peneira de $1 \mathrm{~mm}$.
A determinação dos teores de matéria seca (MS) foi realizada por secagem em estufa a $105^{\circ} \mathrm{C}$ durante 24 horas, e de cinzas por incineração em mufla a $550^{\circ} \mathrm{C}$ por duas horas (Silva e Queiroz, 2002). A fibra em detergente neutro (FDN) e a fibra em detergente ácido (FDA) foram determinadas segundo metodologia descrita por Senger et al. (2008). O teor de nitrogênio total (N) foi determinado pelo método Kjeldahl (Official..., 1995), modificado segundo Kozloski et al. (2003). Para conversão dos valores de N em proteína bruta $(\mathrm{PB})$, foi utilizado o fator de correção de 6,25. A determinação dos teores de extrato etéreo (EE) foi realizada em sistema de refluxo de éter (Soxtherm, Gerhardt, Alemanha) a $180^{\circ} \mathrm{C}$ durante duas horas. Os teores de carboidratos totais (CHT) foram calculados da seguinte maneira CHT $(\%)=100-(\% \mathrm{~PB}+\% \mathrm{EE}$ $+\% \mathrm{CIN})$, e os teores de carboidratos não estruturais (CNE), pela diferença de CHT - FDN. Os valores correspondentes aos nutrientes digestíveis totais (NDT), ao cálcio (Ca) e ao fósforo $(\mathrm{P})$ foram obtidos por Valadares Filho et al. (2006).

No momento em que cada cordeiro ou borrego atingiu o escore de condição preestabelecido, 
estes foram pesados, sendo obtido o peso vivo final (PVF) e iniciado o período de jejum de sólidos, estendendo-se por 14 horas. Após este período, os animais foram novamente pesados, obtendo-se o peso vivo ao abate (PVA). Nessa ocasião, eram também avaliados em relação ao escore de condição corporal (ECC) e à conformação in vivo (CONF) (atribuindo índice de 1 a 5 , com subdivisões de 0,25 , sendo 1 muito pobre e 5 excelente), conforme metodologia adaptada de Osório et al. (1998). O ganho médio diário (GMD) foi obtido por meio do (PVF$\mathrm{PVIn}$ )/dias de confinamento)), e a conversão alimentar (CA) mediante o $(\mathrm{CA}=\mathrm{GMD}$ $(\mathrm{kg}) / \mathrm{CMS}(\mathrm{kg}))$ de cada animal individualmente. As análises de ECC e CONF foram avaliadas considerando a média de avaliadores treinados.

Para a análise dos dados, foi testado o efeito da categoria ovina, do grão e da interação categoria $\mathrm{x}$ grão, pela análise de variância e pelo teste $\mathrm{F}$, adotando-se o nível de 5\% de significância. As médias foram comparadas pelo teste $\mathrm{t}$ de Student, utilizando-se o pacote estatístico Statistical... (2014). O mesmo programa foi utilizado no estudo de correlação entre as variáveis dependentes por meio do cálculo dos coeficientes de correlação de Pearson. O modelo matemático utilizado foi:

$$
Y_{i j k}=\mu+\alpha_{i}+\beta j+(\alpha * \beta)_{i j}+\varepsilon_{i j k}
$$

$\mathrm{Y}_{\mathrm{ijk}}=$ observação referente ao animal $\mathrm{k}$, da categoria animal i e da dieta de alto concentrado $\mathrm{j} ; \mu=$ média geral das observações; $\alpha_{\mathrm{i}}=$ efeito da categoria animal $(\mathrm{i}=$ cordeiro ou borrego $) ; \beta \mathrm{j}=$ efeito da dieta de alto concentrado $(\mathrm{j}=$ milho ou sorgo); $\alpha * \beta=$ efeito da interação; $\varepsilon_{\mathrm{ijk}}=$ erro aleatório associado a cada observação.

As variáveis ECC e CONF foram consideradas contínuas. Os dados foram submetidos à análise residual, sendo: normalidade pelo teste de Shapiro-Wilk $(\mathrm{P} \leq 0,05)$ e observações influentes (outlier), considerando o critério Student $(-3 \leq \mathrm{e} \geq$ $+3)$.

\section{RESULTADOS E DISCUSSÃO}

Para todas as variáveis analisadas neste estudo, não foi verificada interação $(\mathrm{P}>0,05)$ entre a categoria animal (cordeiro e borrego) e a dieta de alto concentrado utilizada (milho ou sorgo) e, portanto, os resultados são apresentados de forma independente.
Foi verificada diferença significativa $(\mathrm{P} \leq 0,05)$ entre as categorias para consumo de matéria seca (CMS), quando esse foi expresso em \% do PV e $\mathrm{g} / \mathrm{kgPV}^{0,75}$ (Tab. 3), o que está de acordo com a afirmativa de Cabral et al. (2008), os quais comentam que há redução linear no CMS (\% do $\mathrm{PV}, \mathrm{g} / \mathrm{kgPV}^{0,75}$ ) com a elevação do peso vivo dos animais, pois animais de menores pesos apresentam superfície corporal maior, sendo, portanto, mais exigentes em energia por unidade de peso metabólico. Esse aspecto explica a superioridade no consumo da categoria de cordeiros em relação aos borregos nessas condições. Rodrigues et al. (2008) avaliaram a substituição parcial ou total do milho moído por polpa cítrica em rações contendo $90 \%$ de concentrado com $10 \%$ de feno de coastcross e observaram valores médios de $3,8 \%$ no consumo em relação ao peso vivo de cordeiros, o que está de acordo com o resultado obtido no presente estudo.

Para o consumo de proteína bruta (CPB), ocorreu diferença significativa $(\mathrm{P} \leq 0,05)$ entre as categorias ( $\mathrm{kg} / \mathrm{dia}, \%$ do $\mathrm{PV}$ e $\left.\mathrm{g} / \mathrm{kg} \mathrm{PV}^{0,75}\right)$, em que os cordeiros apresentaram maior consumo em comparação com os borregos (Tab. 3). Os resultados, expressos em valores absolutos, podem explicar o maior CPB da categoria dos cordeiros em comparação à dos borregos pela maior facilidade de seleção dos alimentos que os animais dessa categoria tiveram,devido ao fato de que os grãos de milho ou de sorgo foram fornecidos inteiros e de que havia maior participação de farelo de soja na sua composição (Tab. 2). Isso permitiu que os cordeiros apresentassem maior capacidade de seleção e de ingestão de farelo de soja e, consequentemente, de proteína bruta, em comparação à categoria dos borregos.

Verifica-se que os cordeiros apresentaram valores superiores para o $\mathrm{CPB}$, em $(\mathrm{kg} / \mathrm{dia})$, em relação aos preditos pelo Nutrient... (2007), o qual preconiza para essa categoria, com expectativa de ganho de peso de $200 \mathrm{~g} \mathrm{dia}^{-1}$ e de peso corporal de $20 \mathrm{~kg}$, um consumo diário de $\mathrm{PB}$ de $116 \mathrm{~g}$. Para a categoria de borregos com peso corporal de $30 \mathrm{~kg}$, são preconizados $129 \mathrm{~g}$ por dia de PB com os mesmos ganhos de peso, portanto recomendação próxima à verificada no presente estudo, o que permite afirmar que foram atendidas as exigências nutricionais desse nutriente para a categoria cordeiro e borregos a partir da formulação da dieta usada. 
Consumo e desempenho...

Tabela 3. Consumo de matéria seca e de nutrientes de cordeiros e borregos alimentados com dietas de alto concentrado de milho ou de sorgo

\begin{tabular}{|c|c|c|c|c|c|c|c|c|}
\hline & \multicolumn{2}{|c|}{ Categoria } & \multicolumn{2}{|c|}{ Grão } & \multicolumn{3}{|c|}{ Probabilidade* } & \multirow[b]{2}{*}{$\begin{array}{l}\mathrm{CV}^{\dagger} \\
(\%)\end{array}$} \\
\hline & Cordeiro & Borrego & Milho & Sorgo & Categoria & Grão & $\begin{array}{c}\text { Categoria } \\
\text { X } \\
\text { Grão }\end{array}$ & \\
\hline CMS & 0,978 & 1,070 & 0,992 & 1,055 & 0,2648 & 0,4320 & 0,2020 & 10,81 \\
\hline $\mathrm{CPB}$ & 0,195 & 0,134 & 0,157 & 0,171 & $<, 0001$ & 0,2056 & 0,0597 & 9,89 \\
\hline CEE & 0,043 & 0,051 & 0,050 & 0,043 & 0,0176 & 0,0323 & 0,2098 & 9,67 \\
\hline CFDN & 0,167 & 0,173 & 0,160 & 0,180 & 0,5783 & 0,1363 & 0,3763 & 10,08 \\
\hline CFDA & 0,073 & 0,072 & 0,059 & 0,087 & 0,6553 & $<, 0001$ & 0,2742 & 0,10 \\
\hline CCHT & 0,694 & 0,834 & 0,736 & 0,793 & 0,0273 & 0,3278 & 0,1878 & 10,91 \\
\hline CCNE & 0,527 & 0,660 & 0,575 & 0,612 & 0,0125 & 0,4130 & 0,1722 & 11,61 \\
\hline CNDT & 0,748 & 0,828 & 0,790 & 0,786 & 0,2164 & 0,9402 & 0,1637 & 10,79 \\
\hline CMS & 3,71 & 3,01 & 3,26 & 3,45 & 0,0016 & 0,4060 & 0,3310 & 8,52 \\
\hline $\mathrm{CPB}$ & 0,74 & 0,37 & 0,53 & 0,57 & $<, 0001$ & 0,1572 & 0,0778 & 7,37 \\
\hline CEE & 0,16 & 0,14 & 0,16 & 0,14 & 0,0252 & 0,0039 & 0,5182 & 7,37 \\
\hline CFDN & 0,64 & 0,49 & 0,53 & 0,60 & $<, 0001$ & 0,0254 & 0,2794 & 7,35 \\
\hline CFDA & 0,27 & 0,21 & 0,20 & 0,29 & 0,0005 & $<, 0001$ & 0,5656 & 3,60 \\
\hline CCHT & 2,63 & 2,34 & 2,40 & 2,58 & 0,0650 & 0,2770 & 0,2930 & 8,62 \\
\hline CCNE & 2,00 & 1,85 & 1,86 & 1,99 & 0,2400 & 0,3624 & 0,2565 & 9,22 \\
\hline CNDT & 2,84 & 2,33 & 2,59 & 2,57 & 0,0024 & 0,8033 & 0,2961 & 8,50 \\
\hline CMS & 84,02 & 73,52 & 76,46 & 81,08 & 0,0421 & 0,4019 & 0,2798 & 8,97 \\
\hline CPB & 16,79 & 9,26 & 12,47 & 13,37 & $<, 0001$ & 0,1641 & 0,0679 & 7,89 \\
\hline CEE & 3,70 & 3,54 & 3,90 & 3,33 & 0,3821 & 0,0070 & 0,3980 & 7,84 \\
\hline CFDN & 14,35 & 11,98 & 12,47 & 13,86 & 0,0070 & 0,1160 & 0,5441 & 8,70 \\
\hline CFDA & 6,32 & 5,26 & 4,67 & 6,91 & 0,0113 & $<, 0001$ & 0,9169 & 9,70 \\
\hline CCHT & 59,64 & 57,33 & 56,35 & 60,62 & 0,5170 & 0,2809 & 0,2500 & 9,06 \\
\hline CCNE & 45,29 & 45,35 & 43,87 & 46,76 & 0,9662 & 0,3656 & 0,2215 & 9,69 \\
\hline CNDT & 64,32 & 56,86 & 60,81 & 60,37 & 0,0563 & 0,8503 & 0,2428 & 8,95 \\
\hline
\end{tabular}

(CMS) consumo de matéria seca; (CPB) consumo de proteína bruta; (CEE) consumo de extrato etéreo; (CFDN) consumo de fibra em detergente neutro; (CFDA) consumo de fibra em detergente ácido; (CCHT) consumo de carboidratos totais; (CCNE) consumo de carboidratos não estruturais; (CNDT) consumo de nutrientes digestíveis totais.

${ }^{\dagger} \mathrm{CV}$ : coeficiente de variação.

$*(\mathrm{P} \leq 0,05)$.

Quando os resultados obtidos foram expressos em $\%$ do $\mathrm{PV}, \mathrm{g} / \mathrm{kgPV}^{0,75}$, os maiores CPB foram para categoria cordeiro em comparação à categoria borrego, sendo esse resultado consequência do maior consumo de matéria seca (\% do PV, $\left.\mathrm{g} / \mathrm{kgPV}^{0,75}\right)$. De acordo com as exigências preditas pelo Nutrient... (2007), os cordeiros necessitam de aproximadamente $57 \%$ a mais de proteína bruta na sua dieta em relação aos borregos. No presente estudo, foi observado um CPB 45,52\% superior nos cordeiros, corroborando o predito por esse sistema.

Em relação à variável consumo de extrato etéreo (CEE), quando expresso em $\mathrm{kg} / \mathrm{dia}$, verifica-se que houve diferença significativa $(\mathrm{P} \leq 0,05)$ entre as categorias testadas, com os borregos apresentando um consumo superior em relação aos cordeiros, resultado este que pode ser atribuído à diferença existente na composição bromatológica das dietas (Tab. 2) em relação a este nutriente. Valores semelhantes foram encontrados por Urano et al. (2006), que trabalharam com rações com alta proporção de concentrado na dieta de cordeiros confinados e observaram consumo médio de $43,8 \mathrm{~g} / \mathrm{dia}$. Já quando o CEE foi expresso em \% do PV, verificou-se superioridade para os cordeiros em relação aos borregos, sendo uma consequência do maior consumo de matéria seca verificado em $\%$ do PV.

Verificaram-se também maiores consumos de fibra em detergente neutro (CFDN) e consumos 
de fibra em detergente ácido (CFDA), expressos em $\%$ do PV e g/kg PV ${ }^{0,75}$, para os cordeiros, resultado esse devido às diferenças encontradas para o consumo de matéria seca ( $\%$ do $\mathrm{PV}$ e g $/ \mathrm{kg}$ $\mathrm{PV}^{0,75}$ ), dad a semelhança desses nutrientes nas dietas.

Para o consumo de carboidratos totais (CCHT) e o consumo de carboidratos não estruturais (CCNE), observou-se diferença significativa $(\mathrm{P} \leq 0,05)$ entre as categorias avaliadas, e os borregos apresentaram maior consumo, em $\mathrm{kg} /$ dia, quando comparados à categoria cordeiro. Esse resultado se justifica pelas diferenças nas concentrações desses nutrientes nas dietas oferecidas aos animais (Tab. 2), o que ocorreu devido ao menor requerimento proteico dos borregos e ao menor teor de PB nas dietas totais, proporcionando uma elevação na concentração de CCHT e CCNE nas dietas deles.

Quando se avaliou o consumo de nutrientes digestíveis totais (CNDT), verificou-se superioridade dos cordeiros em relação aos borregos apenas quando este foi expresso em \% $\mathrm{PV}$, o que também é explicado devido às diferenças de CMS dos animais. O CNDT foi superior, para ambas as categorias, àqueles nutrientes preconizados pelo Nutrient... (2007), o que indica que a exigência desses nutrientes foi atendida pelas dietas.
Ao se avaliarem os consumos em relação ao tipo de grão testado, verificou-se maior CEE $(\mathrm{kg} / \mathrm{dia}$, $\%$ do PV e g/kg PV ${ }^{0,75}$ ) e menor CFDN (\% do $\mathrm{PV}$ ) e CFDA (kg/dia, \% do PV e g/kg $\mathrm{PV}^{0,75}$ ) na dieta à base de grão de milho em comparação à de sorgo (Tab. 3). Essas diferenças são explicadas basicamente pelas distintas proporções desses nutrientes nos grãos, onde o sorgo apresenta menor teor de extrato etéreo e maior de fibra em detergente neutro e de fibra em detergente ácido quando comparado ao milho (Tab. 1 e 2).

Os valores médios referentes ao desempenho das categorias (cordeiros e borregos) e dos grãos testados (milho e sorgo) são apresentados na Tab. 4. Conforme já esperado, o peso vivo ao início do experimento (PVIn) foi superior na categoria dos borregos em relação aos cordeiros, pois estes animais apresentavam aproximadamente um ano a mais de idade e, consequentemente, eram mais desenvolvidos, o que refletiu em maior $(\mathrm{P} \leq 0,05)$ peso vivo final (PVF) e peso vivo ao abate (PVA). Por outro lado, verifica-se que os cordeiros apresentaram superioridade $(\mathrm{P} \leq 0,05)$ quanto ao ganho de peso médio diário (GMD), à conformação in vivo (CONF) e a uma melhor conversão alimentar (CA).

Tabela 4. Características produtivas de cordeiros e borregos alimentados com dietas de alto concentrado de milho ou sorgo

\begin{tabular}{ccccccccc}
\hline & \multicolumn{3}{c}{ Categoria } & \multicolumn{2}{c}{ Grão } & \multicolumn{3}{c}{ Probabilidade* } \\
\cline { 2 - 6 } & Cordeiro & Borrego & Milho & Sorgo & Categoria & Grão & $\begin{array}{c}\text { Categoria } \\
\text { X }\end{array}$ & $\begin{array}{c}\mathrm{CV}^{\dagger} \\
(\%)\end{array}$ \\
& & & & & & & Grão & \\
\hline PVIn (kg) & 22,110 & 33,761 & 27,775 & 28,096 & $<, 0001$ & 0,6846 & 0,2226 & 7,93 \\
ECCIn (1-5) & 2,03 & 2,26 & 2,09 & 2,20 & 0,0539 & 0,3766 & 0,5069 & 7,92 \\
PVF (kg) & 31,89 & 38,05 & 35,02 & 34,93 & $<, 0001$ & 0,9358 & 0,2330 & 8,89 \\
PVA (kg) & 30,484 & 36,855 & 33,730 & 33,610 & $<, 0001$ & 0,9088 & 0,1846 & 8,71 \\
ECCFi (1-5) & 3,06 & 3,10 & 3,07 & 3,09 & 0,4493 & 0,8000 & 0,0842 & 5,59 \\
DA (dias) & 32 & 31 & 34 & 30 & 0,9128 & 0,2115 & 0,4155 & 10,34 \\
GMD (kg) & 0,277 & 0,109 & 0,179 & 0,206 & $<, 0001$ & 0,3505 & 0,0744 & 6,44 \\
CONF (1-5) & 3,26 & 3,00 & 3,15 & 3,10 & 0,0088 & 0,6230 & 0,4144 & 8,51 \\
CA & 4,04 & 8,71 & 5,82 & 6,27 & $<, 0001$ & 0,9949 & 0,0818 & 24,76 \\
\hline
\end{tabular}

(PVIn) peso vivo inicial; (ECCIn) escore de condição corporal inicial; (PVF) peso vivo final; (PVA) peso vivo de abate; (ECCFi) escore de condição corporal final; (DA) dias para abate; (GMD) ganho médio diário; (CONF) conformação subjetiva; (CA) conversão alimentar.

${ }^{\dagger} \mathrm{CV}$ : Coeficiente de variação.

$*(\mathrm{P} \leq 0,05)$ 
Em relação ao GMD, as diferenças encontradas podem ser explicadas pelo aspecto de que os cordeiros estavam em fase inicial de crescimento, quando há uma maior deposição de tecido muscular em relação ao tecido adiposo, o que irá determinar um melhor desempenho dos animais. Entretanto, os borregos encontravam-se em fase avançada de maturidade fisiológica, quando há maior deposição de gordura. Resende et al. (2008) comentam que animais mais velhos depositam mais gordura que animais jovens, assim necessitam de uma demanda maior de energia, condição essa que repercute em menores ganhos de peso diário e, consequentemente, influencia em uma pior conversão alimentar.

Outro fator que pode ter influenciado o melhor desempenho dos cordeiros em comparação aos borregos é o fato de que, conforme já citado acima no texto, havia diferença em relação ao teor proteico das dietas usadas para cada categoria, aspecto esse que, associado à menor ingestão de $\mathrm{MS}\left(\%\right.$ do $\left.\mathrm{PV} \mathrm{g} / \mathrm{kg} \mathrm{PV}^{0,75}\right)$, levou ao menor consumo de PB dos borregos. Essa afirmativa é embasada nos coeficientes de correlação encontrados no presente estudo, entre GMD e CPB (kg/dia, \% do PV e g/kg PV $\left.{ }^{0,75}\right)$, os quais foram significativos e expressivos, sendo: GMD com CPB, em kg, ( $\mathrm{r}=0,85 ; \mathrm{P} \leq 0,001)$; GMD com CPB, em \% do PV, ( $\mathrm{r}=0,84$; $\mathrm{P} \leq 0,001)$; GMD com $\mathrm{CPB}, \mathrm{g} / \mathrm{kg} \mathrm{PV}^{0,75}$, ( $\mathrm{r}=$ $0,85 ; \mathrm{P} \leq 0,001)$.

O peso vivo inicial foi $52,7 \%$ superior para os borregos quando comparados aos cordeiros (Tab. 4). Contudo, devido ao melhor GMD dos cordeiros, essa diferença diminui para apenas $19,32 \%$ em relação ao PVF e para $20,90 \%$ quando se avaliou o PVA, demostrando claramente que a terminação em confinamento apresentada pelos borregos não foi satisfatória. Além disso, deve-se enfatizar que os borregos precisaram ficar retidos na propriedade aproximadamente um ano a mais em relação aos cordeiros, gerando despesas adicionais, risco de perdas por mortalidade, bem como ocupando áreas de campo que poderiam ser utilizadas por matrizes com potencial de produzir um ou mais cordeiros no mesmo período.

Resultados semelhantes em relação ao GMD foram observados por Azeredo et al. (2005), que, ao trabalharem com ovinos da raça Corriedale, machos não castrados, castrados e criptorquidos, abatidos aos 120, 210 e 360 dias de idade, observaram que à medida que se aumentava $o$ peso corporal, os animais apresentavam tendência de diminuição do ganho de peso médio diário, devido à maturidade fisiológica.

Para a conversão alimentar (CA), o resultado do presente estudo concorda com Cabral et al. (2008), que avaliaram a conversão alimentar de ovinos em confinamento dos 20 aos $40 \mathrm{~kg}$ de peso vivo e constataram ineficiência na conversão alimentar dos animais mais pesados em relação aos mais leves. Os mesmos autores reforçaram que o GMD é maior em animais mais leves em relação aos mais pesados, corroborando os resultados do presente estudo.

Quanto à conformação in vivo (CONF) dos animais, a superioridade da categoria dos cordeiros pode ser explicada pelo melhor desenvolvimento muscular desses em relação aos borregos na sua fase inicial de vida. Nesse sentido, cabe salientar que os cordeiros tiveram condição nutricional adequada, com suas exigências nutricionais sendo atendidas mediante as dietas utilizadas no trabalho, no momento de desenvolvimento do tecido muscular. Geraseev et al. (2006) comentam que o nível nutricional é capaz de afetar a fisiologia do animal. Por outro lado, os borregos, na sua fase inicial de vida (quando eram cordeiros), foram criados em pastagem natural, onde não havia a oferta de uma dieta para atender as exigências nutricionais da categoria nem preocupação com isso. Tal aspecto, associado ao metabolismo mais acelerado e ao maior GMD, fez com que os cordeiros apresentassem melhor conformação, diante das mesmas condições de acabamento $(\mathrm{ECC}=3)$, que os borregos.

Quando se avalia o efeito do tipo de grão sobre os resultados de desempenho dos animais (Tab. 4), observa-se que não houve diferença significativa $(\mathrm{P}>0,05)$ para nenhuma das varáveis analisadas. Dessa maneira, pode-se inferir que o uso de dietas de alto concentrado de grão de milho ou de sorgo para terminação de cordeiros e borregos em confinamento apresenta resultados semelhantes.

Nesse sentido, a decisão do tipo de grão a ser utilizado dependerá da conveniência de cada propriedade, seja por disponibilidade do produto ou por características de mercado, como o preço. 
Ambos os grãos podem ser recomendados para o uso de dietas de alto concentrado para terminação de ovinos confinados.

\section{CONCLUSÕES}

Cordeiros terminados em confinamento com dieta de alto concentrado apresentam maior consumo, em percentual e peso metabólico de alimento, quando comparados a borregos. Porém, possuem melhor ganho de peso diário e conversão alimentar, sendo a categoria mais indicada para esse tipo de sistema. Não há diferença quanto ao uso de dietas de alto concentrado à base de grão de milho ou de sorgo, podendo ambos os grãos serem usados para terminação de ovinos em confinamento, quando esse tipo de dieta for utilizada.

\section{REFERÊNCIAS}

ARAÚJO FILHO, J.T.; COSTA, R.G.; FRAGA, A.B. et al. Desempenho e composição da carcaça de cordeiros deslanados terminados em confinamento com diferentes dietas. Rev. Bras. Zootec., v.39, p.363$371,2010$.

AZEREDO, D.M.; OSÓRIO, M.T.M.; OSÓRIO, J.C.S. et al. Crescimento e desenvolvimento de cordeiros corriedale não castrados, castrados e criptorquidas abatidos com diferentes pesos. Rev. Bras. Agroc., v.11, p.339-345, 2005.

CABRAL, L.S.; SANTOS, J.W.; ZERVOUDAKIS, J.T. et al. Consumo e eficiência alimentar em cordeiros confinados. Rev. Bras. Saúde Prod. Anim., v.9, p.703-714, 2008.

GERASEEV, L.C.; PEREZ, J.R.O.; CARVALHO, P.A. et al. Efeitos das restrições pré e pós-natal sobre o crescimento e desempenho de cordeiros Santa Inês do desmame ao abate. Rev. Bras. Zootec., v.35, p.237244, 2006.

KOZLOSKI, G.V.; PEROTTONI, J.; CIOCCA, M.L.S. et al. Potencial nutricional assessment of dwarf elephant grass (Pennisetum purpureum schum. Mott) by chemical composition, digestion and net portal flux of oxygen in catle. Anim. Feed Sci. Technol., v.104, p.29-40, 2003.

MEDEIROS, G.R.; CARVALHO, F.F.R.; BATISTA, A.M.V. et al. Efeito dos níveis de concentrado sobre as características de carcaça de ovinos Morada Nova em confinamento. Rev. Bras. Zootec., v.38, p.718-727, 2009.
MORENO, G.M.B; SILVA SOBRINHO, A.G., LEÃO, A.G. et al. Desempenho, digestibilidade e balanço de nitrogênio em cordeiros alimentados com silagem de milho ou cana-de-açúcar e dois níveis de concentrado. Rev. Bras. Zootec., v.39, p.853-860, 2010.

MORENO, J.A. Clima do Rio Grande do Sul. Porto Alegre: Secretaria da Agricultura, 1961. 41p.

NUTRIENT requirements of small ruminants: sheep, goats, cervids, and new world camelids. Washington: National Academy Press, 2007. 384p.

OFFICIAL methods of analysis. 16.ed. Washington: AOAC, 1995. 1015p

OSÓRIO, J.C.; OSÓRIO, M.T.M.; JARDIM, P.O. Métodos para avaliação da produção de carne ovina: "in vivo" na carcaça e na carne. Pelotas: UFPEL, 1998. $107 \mathrm{p}$.

PAZDIORA, R.D.; PACHECO, R.F.; BRONDANI, I.B. et al. Frequências do fornecimento do alimento no desempenho de vacas e novilhas em confinamento. Arch. Zootec., v.63, p.3-12. 2014.

RESENDE, K.T.; SILVA, H.G.O.; LIMA, L.D. et al. Avaliação das exigências nutricionais de pequenos ruminantes pelos sistemas de alimentação recentemente publicados. Rev. Bras. Zootec., v.37, p.161-177, 2008.

RODRIGUES, G.H.; SUSIN, I.; PIRES, A.V. et al. Substituição do milho por polpa cítrica em rações com alta proporção de concentrado para cordeiros confinados. Cienc. Rural, v.38, p.789-794, 2008.

SENGER, C.C.D.; KOZLOSKI, G.V.; SANCHEZ, L.M.B. et al. Evaluation of autoclave procedures for fiber analysis in forage and concentrate feedstyffs. Anim. Feed Sci. Technol.,v.146, p.169-174, 2008.

SILVA, D.J.; QUEIROZ, A.C. Análise de alimentos: métodos químicos e biológicos. 2.ed. Viçosa: UFV, 2002. 175 p.

SORMUNEN-CRISTIAN, R. Effect of barley and oats on feed intake, live weight gain and some carcass characteristics of fattening lambs. Small Ruminant Res., v.109, p.22-27, 2013.

URANO, F.S.; PIRES, A.V.; SUSIN, I. et al. Desempenho e características da carcaça de cordeiros confinados alimentados com grãos de soja. Pesqui. Agropec. Bras., v.41, p.1525-1530, 2006.

VALADARES FILHO, S.C.; MAGALHÃES, K.A.; ROCHA JUNIOR, V.R. et al. (Eds.). Tabelas brasileiras de composição de alimentos para bovinos. CQBAL 2.0. 2.ed. Viçosa: Suprema Gráfica, 2006. $329 \mathrm{p}$. 